EDUR • Educação em Revista. 2021; 37:e20016 DOI: http://dx.doi.org/10.1590/0102-469820016

() (1) https://creativecommons.org/licenses/by/4.0/

ARTIGO

\title{
O ENSINO RELIGIOSO NA BASE NACIONAL COMUM CURRICULAR: ALGUMAS CONSIDERAÇÕES
}

\author{
TACIANA BRASIL DOS SANTOS ${ }^{1}$ \\ ORCID: https://orcid.org/0000-0002-5742-2429
}

\begin{abstract}
RESUMO: Este artigo discute sobre o Ensino Religioso na Base Nacional Comum Curricular (BNCC), documento resultante das políticas públicas de educação no período da redemocratização brasileira. Atendendo ao previsto na Constituição Federal de 1988, a educação deve formar cidadãos aptos à vivência em uma sociedade democrática. Porém, historicamente, o Ensino Religioso sempre foi ligado a interesses confessionais e políticos. Ainda assim, foi contemplado na BNCC. Através de pesquisa documental, procurou-se compreender o processo de construção do documento, as alterações sofridas pela proposta para o Ensino Religioso ao longo do processo, e as competências e habilidades que se espera que o aluno desenvolva através do conteúdo. Concluiu-se que a presença na BNCC possibilitou um desenvolvimento epistemológico para o Ensino Religioso nunca experimentado até então. O processo democrático de construção do documento conferiu-lhe maior legitimidade, e as escolhas curriculares feitas o adequam aos objetivos para a educação em uma sociedade democrática e cidadã.
\end{abstract}

Palavras-chave: : Ensino Religioso, Base Nacional Comum Curricular, Competências, Habilidades.

\section{RELIGIOUS EDUCATION IN THE NATIONAL COMMON CURRICULAR BASE: SOME CONSIDERATIONS}

\begin{abstract}
This article discusses Religious Education at the National Curriculum Common Base (BNCC), a resulting document from public education policies in Brazil's period of redemocratization. In accordance with the provisions of the Federal Constitution of 1988, education must form citizens capable of living in a democratic society. However, historically, Religious Education has always been linked to confessional and political interests. Even so, it was included in the BNCC. Through documentary research, we sought to understand the process of building this document, the changes undergone by the Religious Education proposal throughout this process, and the skills and abilities that the student has to develop through the subject. We concluded that the inclusion in the BNCC is a possibility of epistemological development of Religious Education never before experienced. The democratic process of building the BNCC gave it greater legitimacy, and the curricular choices suit it to the goals for education in a democratic and citizen society.
\end{abstract}

\footnotetext{
1 Pontifícia Universidade Católica de Minas Gerais (PUC Minas). Bolsista CAPES. Belo Horizonte, MG, Brasil. <tacianabrasil@yahoo.com.br>
} 
Keywords: Religious Education, National Common Curricular Base, Skills, Abilities.

\section{EDUCACIÓN RELIGIOSA EN LA BASE CURRICULAR COMÚN NACIONAL: ALGUNAS CONSIDERACIONES}

RESÚMEN: Este artículo aborda la Educación Religiosa en la Base Común del Currículo Nacional (BNCC), un documento resultante de las políticas de educación pública en el período de la redemocratización brasileña. De conformidad con las disposiciones de la Constitución Federal de 1988, la educación debe formar ciudadanos capaces de vivir en una sociedad democrática. Sin embargo, históricamente, la Educación Religiosa siempre ha estado vinculada a intereses confesionales y políticos. Aun así, lo mismo se incluyó en el BNCC. A través de la investigación documental, buscamos comprender el proceso de construcción de este documento, los cambios sufridos por la propuesta de Educación Religiosa a lo largo de este proceso y las pericias y habilidades que se espera que el estudiante desarrolle a través del contenido. Se concluyó que esta era una posibilidad de desarrollo epistemológico de la Educación Religiosa nunca antes experimentada. El proceso democrático de construcción del BNCC le dio mayor legitimidad, y las elecciones curriculares lo hicieron adecuado para los objetivos de educación en una sociedad democrática y ciudadana.

Palabras clave: Educación religiosa, Base Curricular Nacional Común, Pericias, Habilidades. 


\section{INTRODUÇÃO}

Alvo histórico de polêmicas (CURY, 2004), o Ensino Religioso é o único conteúdo curricular previsto no texto constitucional brasileiro (BRASIL, 2017a). Sua oferta foi iniciada no período colonial e prosseguida durante o Império, sempre sob modelo confessional católico (SAVIANI, 2010). Com a proclamação da República, houve um primeiro momento de ímpeto laicista na educação, que fez com que a disciplina fosse eliminada. Essa iniciativa, porém, não durou muito. Logo sua oferta retornava às escolas, para permanecer até os dias atuais (CUNHA, 2013).

Pode-se dizer que a oferta ou supressão do Ensino Religioso nas escolas públicas brasileiras sempre teve um viés político. Os interesses e anseios da população e dos educadores nunca foram levados em consideração ao se estabelecer legislação sobre o tema. Dessa forma, uma das características do Ensino Religioso no Brasil é, justamente, a construção epistemológica incipiente (CURY, 2004).

Porém, a partir da década de 1970, houve uma maior tendência à construção teórica do Ensino Religioso. Embora não houvesse nenhuma determinação nacional a seu respeito, resoluções, decretos e leis estaduais passaram a orientar as práticas referentes ao conteúdo. Muitas secretarias de educação criaram equipes de estudo e orientação, que elaboraram propostas curriculares para as diferentes séries. Em alguns estados, o Ensino Religioso assumiu um caráter ecumênico ${ }^{2}$ ou interconfessional ${ }^{3}$ (CURY, 2010).

Além disso, várias entidades foram criadas para discutir o assunto, como o Conselho de Igrejas para a Educação Religiosa - CIER, em 1970; Ensino Religioso das Escolas Públicas - EREP, em 1972; Associação Inter-Religiosa de Educação - ASSINTEC, em 1973; e a Comissão Interconfessional para o Ensino Religioso - CIERES, em 1975 (JUNQUEIRA, 2002). Como consequência do trabalho destas organizações, no ano de 1995 foi fundado, em uma reunião do CIER, o Fórum Nacional Permanente de Ensino Religioso - FONAPER, com o objetivo de garantir a oferta de Ensino Religioso em todos os níveis de escolaridade, respeitando a diversidade e a opção religiosa dos educandos. Para isso, a organização se propunha a atuar junto aos Sistemas de Ensino, auxiliando na construção de conteúdos programáticos adequados, que expressassem a ética da dignidade humana (FONAPER, 1995).

Apesar do empenho destas organizações em prol da construção epistemológica do Ensino Religioso, pode-se afirmar que os sistemas educacionais brasileiros ainda careciam de um posicionamento oficial e em nível nacional acerca do modelo, objetivos e formação docente. Principalmente após a redemocratização, com a promulgação da chamada Constituição Cidadã (BRASIL, 2017a) e de toda a legislação educacional que lhe seguiu.

Ao longo da história da educação brasileira, o Ensino Religioso sempre colaborou para a manutenção de um projeto de país, aculturando e conformando os alunos de acordo com o projeto pretendido pelas elites governantes (CUNHA, 2013). Com a redemocratização, esse tipo de utilização não mais seria adequado, posto que o texto constitucional valoriza as liberdades individuais e a diversidade cultural e étnica da população como um fator de composição da nação. Ainda assim, a própria Constituição prevê sua oferta.

Este artigo tem por objetivo discorrer sobre o primeiro documento curricular proposto pelo Ministério da Educação, em nível nacional, que orienta a oferta do Ensino Religioso: a Base Nacional Comum Curricular (BNCC). Criada sob a égide da redemocratização e da legislação educacional pertinente a este período, a BNCC é caracterizada pelo longo processo de construção, permitindo consultas públicas e a docentes e especialistas de cada área do conhecimento.

\footnotetext{
2 O Ensino Religioso de modelo ecumênico, em sua forma mais comum, é caracterizado por uma abordagem que considera elementos congruentes das denominações cristãs (SIQUEIRA, 2012). Sua utilização na escolarização pública é inadequada, pois não considera a diversidade religiosa e a possibilidade de não-crença.

${ }^{3}$ O Ensino Religioso de modelo interconfessional é caracterizado por abordar elementos comuns a várias tradições religiosas, procurando assim atender à maior diversidade religiosa possível. É uma leitura teológica, com referenciais das Ciências Humanas (JUNQUEIRA; NASCIMENTO, 2013). Sua utilização é problemática, pois pressupõe que todos os alunos possuem alguma confissão religiosa, excluindo ateus e agnósticos.
} 
Este trabalho descreve o processo de criação da BNCC, enfocando a evolução da proposta para o Ensino Religioso. Também são analisadas as competências e habilidades atribuídas ao conteúdo na versão homologada do documento.

Estes objetivos foram alcançados através de pesquisa documental, consultando principalmente textos legais, diretrizes educacionais, versões preliminares da BNCC, pareceres do Conselho Nacional de Educação, sítios da internet sobre a construção da BNCC, dentre outros. Em determinados momentos, houve consulta a autores que auxiliaram na compreensão dos textos em análise.

Pode-se considerar que a relevância deste texto é demarcada por vários fatores. Dentre eles, destaca-se a carência de análises de uma proposta curricular original e única na história da educação brasileira, no que tange ao Ensino Religioso. Consultando autores renomados que discorrem sobre a BNCC, como Cury, Reis e Zanardi (2018), Pacheco (2018), e Veiga e Silva (2018), citações ao Ensino Religioso só aparecem na segunda obra referida. Ainda assim, o autor estabelece uma crítica ao modelo confessional do conteúdo, que não é defendido pela BNCC. Por isso, destaca-se a necessidade de pesquisas que estudem adequadamente as proposições deste notável documento sobre o Ensino Religioso enquanto conteúdo e área do conhecimento.

\section{O PROCESSO DE CONSTRUÇÃO DA BNCC}

Para compreender o surgimento da BNCC, é necessário observar as políticas educacionais traçadas após a redemocratização do Brasil. O primeiro documento a discorrer a respeito é a Constituição Federal (BRASIL, 2017a), seguida pela Lei de Diretrizes e Bases da Educação Nacional (LDBEN) $n^{\circ}$ 9.394 de 1996 (BRASIL, 1996) e pela Lei nº 13.005 de 2014, que estabelece o Plano Nacional da Educação (PNE) (BRASIL, 2014a).

O Capítulo III, Seção I da Carta Magna (BRASIL, 2017a) determina um conjunto de princípios que regem a educação no país. Dentre estes, o Artigo 210 estabelece que "Serão fixados conteúdos mínimos para o ensino fundamental, de maneira a assegurar formação básica comum e respeito aos valores culturais e artísticos, nacionais e regionais". Este texto, de acordo com Cury, Reis e Zanardi (2018), é particularmente importante para a valorização da cultura nacional nos processos educativos, salvaguardando a diversidade que existe internamente em nosso país. Para os autores, o documento apresenta uma proposta de "igualdade na diferença" (p. 57).

Herdeira do conceito de base curricular presente na Constituição, a LDBEN 9394/96 traduz como os objetivos da República seriam realizados através da educação (CURY; REIS; ZANARDI, 2018). Seu artigo $9^{\circ}$ instrui que é responsabilidade da União, em colaboração com os Estados e Municípios, estabelecer competências e diretrizes que norteiem os currículos e conteúdos mínimos para a Educação Básica. Distante de instituir um caráter de obrigatoriedade e determinação, o artigo 26 do mesmo documento acrescenta que essas premissas serão levadas a efeito através da criação de uma base nacional comum, que deve ser complementada para atender as peculiaridades dos sistemas de ensino, instituições escolares e características regionais e locais. A LDBEN 9394/96 manifesta a expectativa de que a educação escolar possa ser contextualizada à realidade da população - valorizando, assim, os princípios de pluralidade, diversidade e não discriminação, já previstos na Carta Magna.

Em uma primeira tentativa de atender tais intenções, foram promulgados em 1996 os Parâmetros Curriculares Nacionais (PCN's). Trata-se de uma coleção de dez volumes, sendo o primeiro uma introdução ao documento; seis livros destinados às áreas de conhecimento, a saber: Língua Portuguesa, Matemática, Ciências Naturais, História, Geografia, Arte, Educação Física e Língua Estrangeira $^{4}$; e três volumes dedicados aos Temas Transversais - Ética, Pluralidade Cultural e Orientação Sexual, Meio Ambiente e Saúde (BRASIL, 1997). Macedo (2014) discorre, a respeito deste documento, que o mesmo seria um material de apoio a professores e gestores, sem qualquer obrigatoriedade de sua utilização.

Embora os PCN's tenham representado um avanço na definição de conteúdos em nível nacional, a forma como os conteúdos e metodologias de ensino e aprendizagem foram escolhidos, sem participação e atuação das escolas, foi alvo de muitas críticas (CÂNDIDO; GENTILINI, 2017). Para além disso, e relacionado diretamente à temática deste artigo, deve-se ressaltar que o documento se eximiu

\footnotetext{
${ }^{4}$ Língua Estrangeira é contemplada apenas na versão referente aos Anos Finais do Ensino Fundamental, publicada em 1998.
} 
de qualquer orientação ou direcionamento ao único conteúdo previsto no texto constitucional: o Ensino Religioso.

Assim, ainda no ano de 1997, o FONAPER publicou uma proposta de Parâmetros Curriculares Nacionais para o Ensino Religioso, almejando estabelecer uma identidade única para o conteúdo. Buscando vencer o desafio da confessionalidade, foi adotada uma definição de religião relacionada à reconstrução de significados pela leitura dos elementos do fenômeno religioso (FONAPER, 2009). Embora esta proposição curricular tenha sido amplamente utilizada por docentes da área, a mesma nunca usufruiu do peso da oficialidade governamental, posto que foi publicada como um documento paralelo, uma resposta à ausência do conteúdo nos PCN's.

Prosseguindo na evolução da legislação educacional brasileira, o PNE (BRASIL, 2014a), assumiu um compromisso para a eliminação das desigualdades educacionais. Nesse propósito, estabeleceu estratégias de enfrentamento dos principais problemas: acesso e permanência, desigualdades regionais, formação para o trabalho, exercício da cidadania. O documento é composto por vinte metas, agrupadas no material de divulgação do Ministério da Educação (BRASIL, 2014b) em quatro conjuntos: metas estruturantes para a garantia do direito à educação básica com qualidade; metas de redução da desigualdade e valorização da diversidade; metas de valorização dos profissionais da educação; e metas para o ensino superior.

A necessidade de uma base nacional é reafirmada no PNE, nas metas estruturantes para a garantia do direito à educação básica com qualidade. A Meta 2, em suas estratégias 2.1 e 2.2, determina que se faça uma consulta pública com o intuito de estabelecer objetivos de aprendizagem e desenvolvimento que comporão uma base nacional comum curricular. A Meta 7, estratégia 7.1 reafirma a necessidade da participação inter-federativa no processo, garantindo o respeito à diversidade regional, estadual e local. Assim, a base a ser formulada deveria ter caráter nacional, mas deveria ser acrescida - e nunca eximida - de conteúdos em virtude de suas características regionais.

Em junho de 2015 a Portaria n 592 do Ministério da Educação instituiu uma Comissão de Especialistas para a elaboração de proposta da Base Nacional Comum Curricular. Foram indicados pelo Conselho Nacional de Secretários de Educação - CONSED e pela União Nacional dos Dirigentes Municipais de Educação - Undime 116 especialistas, de todas as unidades da Federação (BRASIL, 2015b). Estes foram divididos em 29 comissões, que deveriam conter ao menos 2 especialistas da área de conhecimento, 1 gestor de secretaria ou professor com experiência em currículo e 1 professor com experiência em sala de aula (MINISTÉRIO DA EDUCAÇÃO, 2018a). A comissão deveria produzir um documento preliminar até o final de fevereiro de 2016. A partir de então, o mesmo passaria por avaliação popular e seria revisto pela mesma comissão (BRASIL, 2015b).

Para redigir a versão preliminar da Base Nacional Comum Curricular, os especialistas consultaram documentos curriculares que já estavam em vigência nos estados, Distrito Federal e municípios de todo o país (MINISTÉRIO DA EDUCAÇÃO, 2018d). Além disso, mais de uma centena de documentos, como legislação, materiais para formação de professores, anais de eventos, relatórios, periódicos e propostas curriculares nacionais e internacionais foram utilizados para fomentar discussões sobre o texto em construção (MINISTÉRIO DA EDUCAÇÃO, 2018b).

O Movimento pela Base Nacional Comum relata, em seu sítio da internet, que foram seguidos sete princípios para orientar a construção da Base, expressos no Quadro 1.

\begin{tabular}{l|l}
\multicolumn{2}{l}{ Quadro $\mathbf{1}$ - Princípios orientadores para construção da Base Nacional Comum Curricular } \\
$\mathbf{0 1}$ & $\begin{array}{l}\text { Foco nos conhecimentos, habilidades e valores essenciais que todos devem aprender para o seu pleno } \\
\text { desenvolvimento e o desenvolvimento da sociedade. }\end{array}$ \\
$\mathbf{0 2}$ & Clareza e objetividade \\
$\mathbf{0 3}$ & Fundamentação em evidências de pesquisas nacionais e internacionais. \\
$\mathbf{0 4}$ & Obrigatoriedade para todas as escolas da Educação Básica do Brasil. \\
$\mathbf{0 5}$ & Diversidade como parte integrante \\
$\mathbf{0 6}$ & $\begin{array}{l}\text { Respeito à autonomia dos sistemas de ensino para a construção de seus currículos, e das escolas para a construção } \\
\text { de seus projetos pedagógicos. }\end{array}$ \\
$\mathbf{0 7}$ & Construção com colaboração entre União, estados e municípios e com a realização de consultas públicas. \\
\hline
\end{tabular}




\section{Fonte: elaborado pela autora com dados extraídos de MOVIMENTO PELA BASE NACIONAL} COMUM (2017c).

Inicialmente, conforme relatado em Ministério da Educação (2016b), era prevista a elaboração do texto preliminar entre fevereiro e setembro de 2015. A seguir, seria realizada uma consulta pública entre setembro de 2015 e março de 2016, que embasaria uma revisão a ser entregue em abril de 2016. O processo prosseguiria com a discussão em seminários municipais e estaduais. Os resultados obtidos baseariam a redação da forma final do documento, que seria repassado ao Conselho Nacional de Educação em junho de 2016.

Ao final do processo de escrita da segunda versão, os seminários apontaram necessidade de revisão de muitos elementos (MOVIMENTO PELA BASE NACIONAL COMUM, 2017d). Assim, o Ministro da Educação instituiu, através da Portaria no 790 (BRASIL, 2016c), o Comitê Gestor da BNCC e Reforma do Ensino Médio. Este comitê tinha por incumbência acompanhar o processo de discussão da segunda versão da Base, e encaminhar a versão final ao Conselho Nacional de Educação.

De acordo com Ministério da Educação (2018a, s.p.), a terceira versão do documento pretendeu solucionar "problemas relativos à clareza e pertinência dos objetivos de aprendizagem identificados na versão dois da Base e apontados durante os seminários". Também procurou-se articular os objetivos de aprendizagem gerais com os de cada área e os específicos de cada componente.

Em 06 de abril de 2017, o Ministério da Educação entregou a terceira versão da BNCC ao Conselho Nacional de Educação (MOVIMENTO PELA BASE NACIONAL COMUM, 2017a). Após análise do órgão e uma série de audiências públicas, a Base foi aprovada por 20 votos a três (MOVIMENTO PELA BASE NACIONAL COMUM, 2017b). A Resolução CNE/CP n²2 (BRASIL, 2017b) instituiu e orientou a implantação do documento em todo o país.

A versão de 2017 da BNCC apresenta diretrizes para a Educação Infantil e Ensino Fundamental. Apenas em dezembro de 2018 foi homologado o documento referente ao Ensino Médio. A BNCC organiza o Ensino Fundamental em cinco áreas do conhecimento que englobam os componentes curriculares, a saber: área das Linguagens, com os componentes Língua Portuguesa, Arte, Educação Física e Língua Inglesa; área da Matemática, com o componente Matemática; área das Ciências da Natureza, com o componente Ciências; área das Ciências Humanas, com os componentes Geografia e História; e área do Ensino Religioso, com o componente homólogo (BRASIL, 2018).

Destaca-se, no processo de construção da BNCC, o caráter de participação popular. As críticas referentes à falta de consulta popular verificada por ocasião da promulgação dos Parâmetros Curriculares Nacionais definitivamente não são aplicáveis à BNCC. Três níveis de consulta foram realizados. Na primeira versão, 12 milhões de contribuições foram alcançadas através de consulta pública. Na segunda versão, 27 seminários estaduais oportunizaram a contribuição de 9 mil professores. O Comitê Gestor, composto por sete titulares e sete suplentes, também ofereceu sua contribuição. Por fim, o documento passou por análise do Conselho Nacional de Educação e por audiências públicas. O processo de avaliação e construção da BNCC está representado também na Figura 1. 


\section{Figura 1 - Processo de construção e avaliação da BNCC}

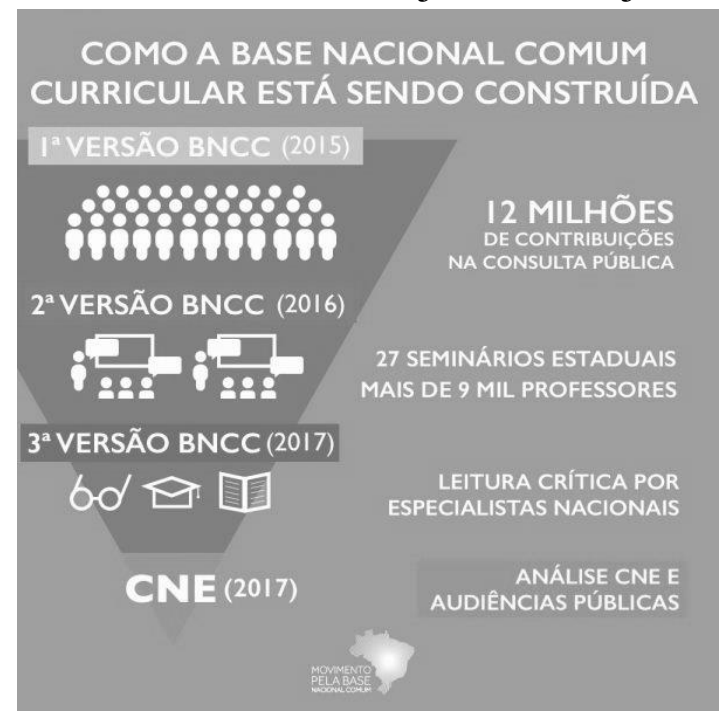

Fonte: MOVIMENTO PELA BASE NACIONAL COMUM, (2017a).

Acerca da redação da BNCC, autores como Aguiar (2018) ponderam que pode ser considerada "fruto de disputas de concepções e de procedimentos (...) influenciadas, sobretudo, por atores externos ao governo" (AGUIAR, 2018, p. 734). É fato que muitas entidades não governamentais insuflaram o processo de construção do documento, sobretudo após o impeachment da presidenta Dilma Rousseff, da troca do corpo ministerial e de alterações na metodologia de formulação e revisão. Porém, não se pode desconsiderar que, pela primeira vez, houve consulta popular para construção de um documento curricular. Ainda que outros atores sociais tenham influenciado a formulação da BNCC certamente, muito mais que a população -, a simples existência da possibilidade de expressão por parte dos cidadãos, durante a construção do documento, pode ser considerada um importante passo na democratização das construções curriculares.

O prazo para implementação da BNCC em sala de aula é de até dois anos após sua homologação - período que foi utilizado pelo Ministério da Educação para estabelecer o diálogo com as redes de ensino acerca das etapas de implementação e preparação necessárias (MINISTÉRIO DA EDUCAÇÃO, 2018). O caráter de adaptação contextual da BNCC, longe de torná-la excessivamente plástica, convida as instituições escolares, redes de escolas e sistemas de ensino a adotar suas próprias formas de organização e propostas de progressão, desde que atendam a todos os direitos e objetivos de aprendizagem instituídos na BNCC. definidas como

As aprendizagens essenciais, denominadas no documento competências, podem ser

\footnotetext{
a mobilização de conhecimentos (conceitos e procedimentos), habilidades (práticas cognitivas e socioemocionais), atitudes e valores, para resolver demandas complexas da vida cotidiana, do pleno exercício da cidadania e do mundo do trabalho. (BRASIL, 2017b, p. 4).
}

As competências são um dos elementos essenciais da BNCC. Através delas, torna-se possível oferecer uma identidade de conhecimentos a todos os estudantes da Educação Básica brasileira. Conforme Cury, Reis e Zanardi (2018), essa característica é um diferencial do documento, que visa corrigir a desigualdade de oportunidades através da oferta de conteúdos idênticos em todas as escolas.

Para além do combate às desigualdades, a BNCC também objetiva ser um projeto de sociedade. O documento propõe um modelo de educação integral, que oferece conhecimentos variados, mas que também promove o autoconhecimento e a alteridade, ampliando a visão de mundo e capacitando à leitura da realidade e reconhecimento da própria identidade cultural. Assim, pode-se afirmar que a BNCC auxilia na transformação da sociedade, promovendo um viés mais democrático (NEIRA; ALVIANO JÚNIOR; ALMEIDA, D., 2016). 
Conforme dito anteriormente, a BNCC teve um processo de escrita e revisão em várias etapas, havendo três versões para o texto: a inicial (BRASIL, 2015a), a segunda, já revisada (BRASIL, 2016a), e a terceira, homologada (BRASIL, 2018).

Embora o conteúdo alvo deste estudo apareça nas três versões do texto, importantes alterações podem ser percebidas entre uma versão e outra. A iniciar pelo fato de que nas duas primeiras versões (BRASIL, 2015a, 2016a) a área de Ciências Humanas é composta pelos conteúdos História, Geografia, Ensino Religioso, Filosofia e Sociologia, enquanto que a versão homologada (BRASIL, 2018) separa o Ensino Religioso como uma área do conhecimento. Esta alteração incita à observação das diferenças entre as três versões da BNCC.

Quadro 2 - Comparação entre as versões do texto da área de Ciências Humanas na BNCC

\begin{tabular}{|c|c|c|c|}
\hline & BNCC 1 & BNCC 2 & BNCC 3 \\
\hline$\frac{0}{\frac{0}{0}}$ & $\begin{array}{c}\text { Estudo da existência } \\
\text { humana e das intervenções } \\
\text { sobre a vida. }\end{array}$ & Vida intelectual moderna. & $\begin{array}{l}\text { Conjunto de objetos de conhecimento que } \\
\text { favoreçam o desenvolvimento de } \\
\text { habilidades e que aprimorem a capacidade } \\
\text { de os alunos pensarem diferentes culturas e } \\
\text { sociedades. }\end{array}$ \\
\hline$\frac{\sum_{0}^{\circ}}{0}$ & $\begin{array}{l}\text { Compreender e } \\
\text { problematizar as ações e } \\
\text { relações individuais e } \\
\text { coletivas. }\end{array}$ & $\begin{array}{l}\text { Compreender o mundo como } \\
\text { processo, em construção } \\
\text { aberta à intervenção humana. }\end{array}$ & $\begin{array}{l}\text { Desenvolver raciocínio espaço-temporal, } \\
\text { estimulando a formação ética e o } \\
\text { desenvolvimento da capacidade de } \\
\text { observação. }\end{array}$ \\
\hline ن & $\begin{array}{l}\text { Geografia, História, ER } \\
\text { (apenas no EF), Filosofia } \\
\text { (apenas no EM) e } \\
\text { Sociologia (apenas no EM). }\end{array}$ & $\begin{array}{l}\text { Geografia, História, Filosofia } \\
\text { (apenas no EM) e Sociologia } \\
\text { (apenas no EM). }\end{array}$ & $\begin{array}{l}\text { Geografia, História, Filosofia (apenas no } \\
\text { EM) e Sociologia (apenas no EM). }\end{array}$ \\
\hline
\end{tabular}

Fonte: Elaborado pela autora com dados extraídos de Brasil (2015a, 2016a, 2018)

Em sua primeira versão (BRASIL, 2015a), a Base define que a área de Ciências Humanas tem como objeto de estudo a existência humana e as intervenções sobre a vida. Seu principal pressuposto atribui ao ser humano o protagonismo por sua existência. A partir destes princípios, cada conteúdo contribui para a construção do conhecimento a partir de suas especificidades. Ao longo do Ensino Fundamental, Geografia, História e Ensino Religioso cooperam no processo de compreensão e problematização das ações e relações individuais e coletivas. Note-se que a análise de processos e fenômenos religiosos e a problematização de instituições religiosas figuram entre objetivos da área.

A segunda versão (BRASIL, 2016a, p. 152-153) define como objeto das Ciências Humanas a "vida intelectual moderna, que problematiza, em suas dimensões, o mundo feito e/ou afetado pela ação humana". A composição dos conteúdos é idêntica à versão anterior, sendo-lhes atribuída a função de problematizadora, formativa e transformadora

dos indivíduos e das relações sociais e de poder, o pensamento, os conhecimentos e as religiões, as culturas e suas normas, as políticas e as leis, os tempos e os processos históricos, as formas espaciais de organização cultural e política e as relações (incluindo as representações) com a natureza (BRASIL, 2016a, p. 153).

Conclui-se, portanto, que as religiões também seriam objeto de análise da área de Ciências Humanas, de acordo com a segunda versão.

A terceira versão (BRASIL, 2018) elenca um conjunto de objetos de conhecimento, visando desenvolver as habilidades descritas no documento e aperfeiçoar a capacidade de pensar diferentes 
culturas e sociedades. O Ensino Religioso não mais faz parte da área de Ciências Humanas. Adaptado em uma área análoga, tornou-se responsável pela discussão de todas as questões relacionadas ao fenômeno religioso como elemento constitutivo das narrativas de sentido individuais e coletivas, bem como da dinâmica das sociedades humanas. Esta organização contradiz o que havia sido deliberado nas duas primeiras versões da BNCC.

Percebe-se, portanto, que a retirada do Ensino Religioso da área de Ciências Humanas representou uma limitação da previsão de diálogo. Com os conteúdos unidos sob uma mesma área, e compartilhando objetivos de aprendizagem, a influência da religião na construção de sentidos individuais e coletivos necessariamente deveria colaborar para o trabalho realizado em prol da compreensão do ser humano, dos processos sociais e das instituições. Ao criar uma área específica para o Ensino Religioso, a versão final da BNCC (BRASIL, 2018) afasta a discussão sobre o fenômeno religioso desse processo. Tal opção curricular empobrece as Ciências Humanas, ao lhe eximir da discussão sobre a influência do fenômeno religioso na sociedade; sobrecarrega o Ensino Religioso, ao lhe impor discussões que seriam mais adequadas à Geografia ou História; e limita o trabalho docente, posto que áreas distintas não compartilham objetivos específicos de aprendizagem.

Por outro lado, considerando a falta de legitimidade e crises epistemológicas enfrentadas pelo Ensino Religioso (CURY, 2004), estabelecer-lhe uma área específica pode ajudar no processo de consolidação dos pressupostos de seu modelo laico em todo o território nacional. A visibilidade atribuída ao conteúdo, associada à unificação curricular, pode produzir efeitos benéficos à sua construção teórica e metodológica.

É necessário, porém, observar que a mesma Resolução que institui e orienta a implantação da BNCC (BRASIL, 2017b) cria a possibilidade de retorno do Ensino Religioso para a área de Ciências Humanas, conforme se pode ler no trecho a seguir:

Art. 23. O CNE, mediante proposta de comissão específica, deliberará se o ensino religioso terá tratamento como área do conhecimento ou como componente curricular da área de Ciências Humanas, no Ensino Fundamental. (BRASIL, 2017b, p. 12).

De fato, em 08 de outubro de 2019, menos de dois anos após a publicação da versão final da BNCC, o Conselho decidiu que o Ensino Religioso deixa de ser área de conhecimento, e passa, enquanto conteúdo curricular, a integrar as Ciências Humanas (BRASIL, 2019a; 2019b). Caso essa decisão tivesse sido tomada antes da homologação da BNCC, teria sido possível adotar uma redação mais próxima à $2^{\mathrm{a}}$ versão da Base, mantendo os benefícios de um diálogo mais aproximado entre o Ensino Religioso e as demais Ciências Humanas. Resta, portanto, questionar como se dará esse intrcâmbio entre os conteúdos nas futuras revisões da BNCC.

Ao analisar os pressupostos para o Ensino Religioso nas diferentes versões da Base Nacional Comum Curricular, percebe-se uma concordância acerca do objeto do conteúdo, delimitado como o conhecimento religioso. Apenas o enfoque foi alterado: nas duas primeiras versões, priorizava-se a perspectiva da diversidade nas análises (BRASIL, 2015a, 2016a); enquanto que a versão final valoriza os pressupostos éticos e científicos (BRASIL, 2018).

Acerca do objeto do Ensino Religioso, é importante observar que se trata de uma questão sobre a qual não há concordância, nem entre pesquisadores da área, nem entre docentes (SCHOCK, 2012). Ainda assim, os redatores da BNCC não oscilaram acerca da definição do objeto em nenhuma versão do texto. Destaque-se que, como foi visto no Quadro 2, não há consenso entre as três versões do documento acerca do objeto da área de Ciências Humanas, evidenciando que era possível discutir e alterar os elementos epistemológicos conforme o propósito almejado. 
Quadro 3 - Comparação entre as versões do texto sobre Ensino Religioso na Base Nacional Comum Curricular

\begin{tabular}{|c|c|c|c|}
\hline & BNCC 1 & BNCC 2 & BNCC 3 \\
\hline$\frac{\stackrel{0}{0}}{\frac{0}{0}}$ & $\begin{array}{l}\text { Conhecimento religioso, em } \\
\text { uma perspectiva de } \\
\text { diversidade. }\end{array}$ & $\begin{array}{l}\text { Conhecimento religioso, em } \\
\text { uma perspectiva de } \\
\text { diversidade. }\end{array}$ & $\begin{array}{c}\text { Conhecimento religioso, a partir de pressupostos } \\
\text { éticos e científicos. }\end{array}$ \\
\hline$\frac{\overbrace{0}^{2}}{\frac{0}{0}}$ & $\begin{array}{l}\text { Assegurar o conhecimento da } \\
\text { diversidade religiosa, } \\
\text { garantindo que ela seja } \\
\text { respeitada, vedadas quaisquer } \\
\text { formas de proselitismos. }\end{array}$ & $\begin{array}{l}\text { Educação para o diálogo e } \\
\text { convívio entre pessoas } \\
\text { religiosas, agnósticas e sem } \\
\text { religião. }\end{array}$ & $\begin{array}{c}\text { Proporcionar a aprendizagem dos } \\
\text { conhecimentos religiosos, culturais e estéticos, a } \\
\text { partir das manifestações religiosas percebidas na } \\
\text { realidade dos educandos. } \\
\text { Propiciar conhecimentos sobre o direito à } \\
\text { liberdade de consciência e de crença, no } \\
\text { constante propósito de promoção dos direitos } \\
\text { humanos. } \\
\text { Desenvolver competências e habilidades que } \\
\text { contribuam para o diálogo entre perspectivas } \\
\text { religiosas e seculares de vida, exercitando o } \\
\text { respeito à liberdade de concepções e o } \\
\text { pluralismo de ideias, de acordo com a } \\
\text { Constituição Federal. } \\
\text { Contribuir para que os educandos construam } \\
\text { seus sentidos pessoais de vida a partir de valores, } \\
\text { princípios éticos e da cidadania. }\end{array}$ \\
\hline 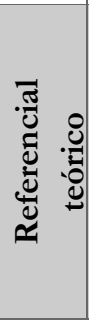 & $\begin{array}{l}\text { ER próximo e conectado } \\
\text { com História, Geografia, } \\
\text { Sociologia e Filosofia, } \\
\text { estabelecendo e ampliando } \\
\text { diálogos e abordagens } \\
\text { teórico-metodológicas que } \\
\text { transcendam as fronteiras } \\
\text { disciplinares. }\end{array}$ & $\begin{array}{l}\text { Seleção de conhecimentos } \\
\text { das Ciências Humanas e } \\
\text { Sociais. }\end{array}$ & $\begin{array}{l}\text { O conhecimento religioso é produzido no } \\
\text { âmbito das diferentes áreas do conhecimento } \\
\text { científico das Ciências Humanas e Sociais, } \\
\text { notadamente da Ciências da Religião. }\end{array}$ \\
\hline
\end{tabular}

Fonte: elaborado pela autora com dados extraídos de Brasil (2015a, 2016a, 2018)

Acerca dos pressupostos para o Ensino Religioso elencados na versão homologada da BNCC (BRASIL, 2018), é possível que a mudança de enfoque tenha se dado não apenas por questões epistemológicas. A invocação de pressupostos éticos e científicos pode ter o propósito de indicar que a área não mais corresponde ao Ensino Religioso de modelo confessional experimentado no passado, e sim a um tratamento científico da questão religiosa, acessível a todos os alunos.

É interessante ressaltar que, durante o processo de escrita do texto da Base Nacional Comum Curricular, em resultado da Ação Direta de Inconstitucionalidade n. 4.439, relacionada à oferta de Ensino Religioso confessional (PEREIRA, 2010), o Supremo Tribunal Federal decidiu, por maioria de votos, que o Ensino Religioso nas escolas públicas poderia ter natureza confessional (STF..., 2017). Apesar dessa decisão, em nenhuma das versões do texto cogitou-se a adoção deste modelo para o conteúdo. Sequer modelos como o interconfessional e o ecumênico foram cogitados. Ainda assim, o texto não problematiza o conceito de laicidade.

Existe uma possibilidade que explica a ausência de um debate sobre o conceito de laicidade no texto da BNCC. Ele diz respeito à identidade e pertencimento dos redatores da área/conteúdo. Conforme indica Cunha (2016), todos eles eram membros do FONAPER - inclusive, um deles era seu coordenador nacional. Um dos objetivos do trabalho do FONAPER é, justamente, fomentar modelos laicos de Ensino Religioso escolar. Talvez, por estarem habituados à discussão em um ambiente de formação e militância, os redatores tenham considerado desnecessário levar a discussão ao texto, apenas aplicando os conceitos.

Em tempo, deve-se ressaltar que o FONAPER, ao longo dos últimos 25 anos, teve uma considerável evolução epistemológica. Os Parâmetros Curriculares Nacionais para o Ensino Religioso (FONAPER, 2009) caracterizavam-se por uma considerável influência da Teologia e Religiões Comparadas. Ao longo das últimas décadas, a formulação epistemológica da instituição evoluiu em 
direção a um modelo de Ensino Religioso cuja laicidade se fundamenta na valorização da diversidade, conforme se pode ler no texto de Ricardo de Oliveira (2020), publicado no portal da instituição.

Conclui-se, portanto, que os redatores optaram por não levar a discussão sobre o conceito de laicidade para o documento - embora não tenham, em nenhum momento, feito afirmações contraditórias sobre essa premissa. Por ocasião de futuras revisões da BNCC, seria importante inserir essa discussão. Em primeiro lugar, porque ajuda o leitor a compreender os objetivos do Ensino Religioso. Depois, porque o desenvolvimento epistemológico que se espera para o conteúdo poderá alimentar outras correntes teóricas, e as premissas do FONAPER podem deixar de ser hegemônicas em nosso país.

Retomando a discussão acerca dos objetivos para o Ensino Religioso, percebe-se que estes foram alterados ao longo do processo de edição da Base. É interessante pensar que se os objetivos são aquilo que se pretende atingir através do objeto, e se o objeto praticamente não foi alterado, por que os objetivos sofreram alterações tão severas? Ressalte-se que a primeira e segunda versões do documento (BRASIL, 2015a, 2016a) basicamente versam sobre o respeito e o convívio entre indivíduos com diferentes opções religiosas, enquanto que a versão final (BRASIL, 2018) apresenta uma lista composta por quatro objetivos, relacionados ao conhecimento religioso, liberdade de crença, diálogo religioso e construção de um sentido de vida. Considera-se, portanto, que a crise de definição do objeto do Ensino Religioso não foi adequadamente enfrentada pelos redatores da área, manifestando-se posteriormente na definição dos objetivos elencáveis.

A escolha do referencial teórico que sustenta o Ensino Religioso escolar também não é unânime entre as versões da Base. Na primeira versão (BRASIL, 2015a), quando o conteúdo ainda fazia parte das Ciências Humanas, sua proximidade e conexão com os demais integrantes da área estimulava diálogos e abordagens que deveriam ultrapassar suas fronteiras disciplinares. A segunda versão (BRASIL, 2016a) compreende que o Ensino Religioso será referenciado em uma seleção de conhecimentos oriundos das Ciências Humanas e Sociais. A terceira e definitiva versão (BRASIL, 2018) compreende que o conhecimento religioso, objeto do conteúdo, é "produzido no âmbito das diferentes áreas do conhecimento científico das Ciências Humanas e Sociais, notadamente da(s) Ciência(s) da(s) Religião(ões)" (BRASIL, 2018, p. 434).

Cabe observar que a definição apresentada pelas primeira e segunda versões da BNCC (BRASIL, 2015a, 2016a) não consideram o Ensino Religioso uma transposição didática das Ciências da Religião (JUNQUEIRA, 2013), mas uma abordagem diferenciada dos temas que serão trabalhados pelas Ciências Humanas. A terceira versão do texto (BRASIL, 2018) demarca as Ciências da Religião como espaço preferencial de produção do conhecimento. A definição de uma ciência como referência pode ser considerada um ganho para o conteúdo, uma vez que lhe demarca a identidade e a validação científica. E, em certa medida, lhe provê um espaço de construção do conhecimento separado dos outros conteúdos que integram as Ciências Humanas - o que é, no mínimo, irônico, posto que para a CAPES as Ciências da Religião integram a Grande Área de Ciências Humanas (MINISTÉRIO DA EDUCAÇÃO, 2018c).

\section{O ENSINO RELIGIOSO NA VERSÃO FINAL DA BNCC: CONSIDERAÇÕES SOBRE COMPETÊNCIAS E HABILIDADES}

Enquanto proposta curricular, a BNCC estabelece competências gerais que devem ser almejadas em todo o processo educativo. Cada área do conhecimento possui suas próprias competências específicas, que devem dialogar com as gerais. Não diferente das demais áreas, o Ensino Religioso possui suas próprias competências específicas, a saber:

\section{COMPETÊNCIAS ESPECÍFICAS DE ENSINO RELIGIOSO PARA O ENSINO FUNDAMENTAL}

1. Conhecer os aspectos estruturantes das diferentes tradições/movimentos religiosos e filosofias de vida, a partir de pressupostos científicos, filosóficos, estéticos e éticos.

2. Compreender, valorizar e respeitar as manifestações religiosas e filosofias de vida, suas experiências e saberes, em diferentes tempos, espaços e territórios.

3. Reconhecer e cuidar de si, do outro, da coletividade e da natureza, enquanto expressão de valor da vida.

4. Conviver com a diversidade de crenças, pensamentos, convicções, modos de ser e viver. 
5. Analisar as relações entre as tradições religiosas e os campos da cultura, da política, da economia, da saúde, da ciência, da tecnologia e do meio ambiente.

6. Debater, problematizar e posicionar-se frente aos discursos e práticas de intolerância, discriminação e violência de cunho religioso, de modo a assegurar os direitos humanos no constante exercício da cidadania e da cultura de paz. (BRASIL, 2018, p. 435).

Analisando comparativamente as competências específicas da área de Ciências Humanas, percebe-se que dialogam diretamente com as de Ensino Religioso. A importância da identidade, do reconhecimento da filiação social e cultural, do respeito e valorização da diversidade, do cuidado com a natureza e do bem comum encontram-se expressos nas duas áreas, e poderiam dialogar sem maiores dificuldades caso compusessem um único corpo de objetivos de aprendizagem. Esta, porém, não foi a escolha da equipe que organizou e redigiu a versão final da BNCC - o que limitou as possibilidades de diálogo para o Ensino Religioso, mas concedeu-lhe maior clareza quanto às competências que lhe são próprias.

O conteúdo a ser trabalhado em Ensino Religioso, para alcançar as competências acima descritas, foi organizado em três unidades temáticas. A unidade Identidades e Alteridades, que ocorre apenas nos anos iniciais do Ensino Fundamental, enfatiza a percepção e respeito às diferenças, e construção da identidade. A unidade Manifestações Religiosas trabalha questões referentes aos símbolos, ritos, espaços, territórios e lideranças religiosas, visando oferecer conhecimento sobre as diversas tradições e respeito às distintas experiências e manifestações religiosas. Por fim, a Unidade Crenças Religiosas e Filosofias de Vida trabalha os mitos, crenças, narrativas, doutrinas e tradições dos grupos religiosos e filosofias de vida.

Cada Unidade Temática possui Objetos de Conhecimento, que abrigam Habilidades que se almeja que o aluno desenvolva através do conteúdo. São ao todo 30 Objetos e 63 Habilidades, distribuídos da seguinte maneira:

Tabela 1 - Objetos de Conhecimento e Habilidades por Unidade Temática

\begin{tabular}{|c|c|c|c|c|c|c|}
\hline \multirow[b]{2}{*}{$\begin{array}{l}\text { Ano do } \\
\text { EF }\end{array}$} & \multicolumn{2}{|c|}{ Identidades e Alteridades } & \multicolumn{2}{|c|}{ Manifestações Religiosas } & \multicolumn{2}{|c|}{$\begin{array}{c}\text { Crenças Religiosas e Filosofias } \\
\text { de Vida }\end{array}$} \\
\hline & $\begin{array}{c}\text { Objeto de } \\
\text { Conhecimento }\end{array}$ & Habilidade & $\begin{array}{c}\text { Objeto de } \\
\text { Conhecimento }\end{array}$ & Habilidade & $\begin{array}{c}\text { Objeto de } \\
\text { Conhecimento }\end{array}$ & Habilidade \\
\hline $1^{\circ}$ & 2 & 4 & 1 & 2 & - & - \\
\hline $2^{\circ}$ & 3 & 5 & 1 & 2 & - & - \\
\hline $3^{\circ}$ & 1 & 2 & 2 & 4 & - & - \\
\hline $4^{\circ}$ & - & - & 2 & 5 & 1 & 2 \\
\hline $5^{\circ}$ & - & - & - & - & 3 & 7 \\
\hline $6^{\circ}$ & - & - & - & - & 3 & 7 \\
\hline $7^{\circ}$ & - & - & 2 & 5 & 2 & 3 \\
\hline $8^{\circ}$ & - & - & - & - & 4 & 7 \\
\hline $9^{\circ}$ & - & - & - & - & 3 & 8 \\
\hline TOTAL & 6 & 11 & 8 & 18 & 16 & 34 \\
\hline
\end{tabular}

Fonte: elaborado pela autora com dados extraídos de Brasil (2018)

Percebe-se, através da Tabela 1, que a Unidade Temática Identidades e Alteridades só aparece nos três primeiros anos do Ensino Fundamental, não retornando em nenhum momento posterior. A Unidade Manifestações Religiosas aparece do $1^{\circ}$ ao $4^{\circ}$ ano, retornando pontualmente no $7^{\circ}$. Crenças Religiosas e Filosofias de Vida, por sua vez, surge pela primeira vez no $4^{\circ}$ ano, e permanece até o $9^{\circ}$, sendo a única Unidade Temática trabalhada na maior parte dos anos $\left(5^{\circ}, 6^{\circ}, 8^{\circ}\right.$ e $\left.9^{\circ}\right)$.

A diferença quantitativa de Objetos e Habilidades entre as Unidades Temáticas de Ensino Religioso é premente, como se pode perceber através do gráfico: 
Figura 2 - Objetos de Conhecimento e Habilidades por Unidade Temática

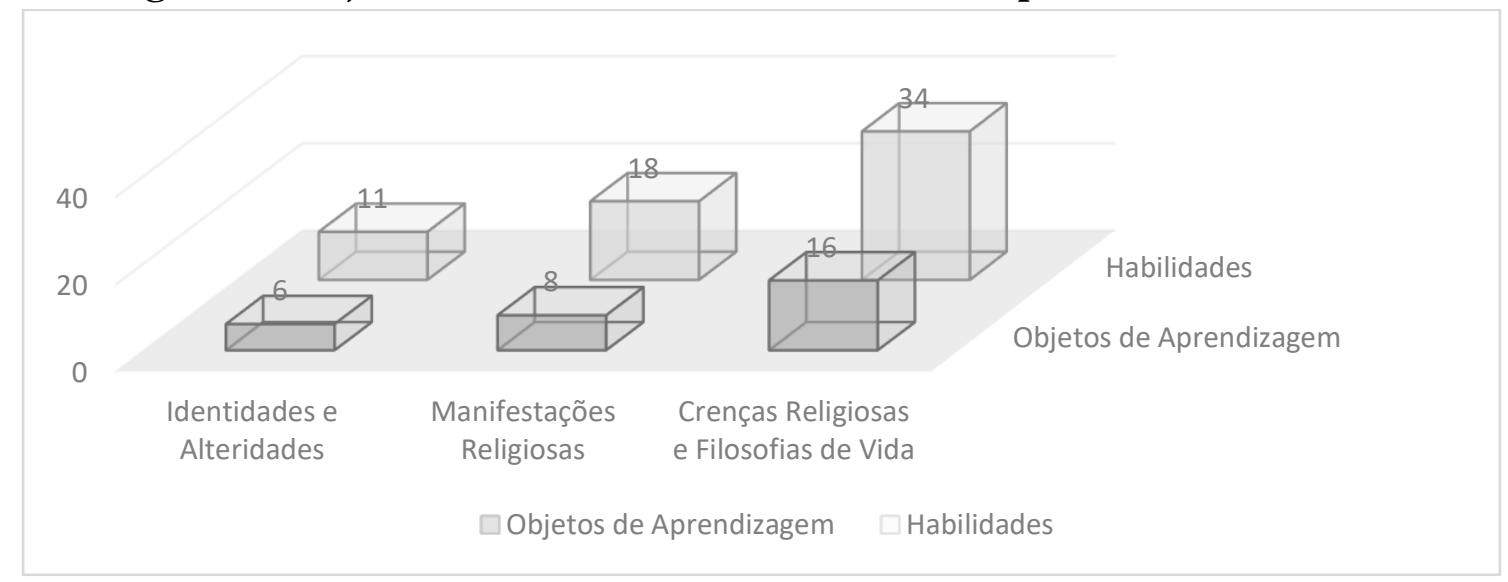

Fonte: elaborado pela autora com dados extraídos de Brasil (2018)

A observação destes dados conduz à formulação de hipóteses que os expliquem. Em um primeiro momento, há que se questionar o fato de as unidades Identidades e Alteridades e Crenças Religiosas e Filosofias de Vida nunca aparecerem paralelamente em um mesmo ano do Ensino Fundamental. É possível que a primeira tenha sido considerada uma introdução ao trabalho desta última. Assim, no início do Ensino Fundamental seria feita uma introdução ao pensamento religioso, considerando a própria identidade e o respeito à diferença, para então prosseguir à análise das crenças de uma forma geral. Manifestações Religiosas, nesse caso, seria a unidade responsável por estabelecer um elo entre aquelas que portariam o fio condutor do conteúdo.

Para além dessa hipótese, uma análise quantitativa dos dados pode sugerir que tenha sido atribuída maior importância à Unidade Temática Crenças Religiosas e Filosofias de Vida (34 Habilidades), seguida por Manifestações Religiosas (18 Habilidades), e por último por Identidades e Alteridades (11 Habilidades). Nesse caso, pode-se supor que o foco de análise do conhecimento religioso, objeto do conteúdo na BNCC, seja o pensamento expresso nas crenças e filosofias, em detrimento às práticas presentes nas manifestações religiosas. O reconhecimento da própria identidade e da alteridade, nesse caso, seria importante para a adoção de um posicionamento pessoal sobre o tema, sem, contudo, desrespeitar os demais.

Considerando conjuntamente a forma de dispersão das Unidades Temáticas ao longo dos anos do Ensino Fundamental, bem como os aspectos quantitativos de Objetos de Conhecimento e Habilidades de cada Unidade, confirma-se a existência de uma trajetória de desenvolvimento das competências almejadas na BNCC. O processo educativo inicia com a percepção das diferenças e construção de uma identidade, prossegue com o reconhecimento de ações e práticas ligadas ao fenômeno religioso, e se desenvolve em direção à compreensão do pensamento religioso ou filosófico que motiva os indivíduos em suas ações.

Esta tese pode ser corroborada mais uma vez através da análise do vocabulário escolhido para a construção das Habilidades em cada Unidade Temática. Em Identidades e Alteridades, nos primeiros anos do Ensino Fundamental, são utilizados verbos que compõe um campo semântico próprio do tema: identificar, acolher, reconhecer, valorizar, distinguir, respeitar, caracterizar. Em Manifestações Religiosas, embora o vocabulário seja bastante semelhante, percebe-se a introdução de dois verbos que remetem ao reconhecimento do fenômeno religioso: exemplificar e discutir. A Unidade Crenças Religiosas e Filosofias de Vida, que possui o vocabulário mais amplo das três, é a única que utiliza verbos que remetem à reflexão e à tomada de posição pessoal: analisar, debater e construir. 
Tabela 2 - Quantitativo dos verbos utilizados nas Habilidades de Ensino Religioso na BNCC

\begin{tabular}{|l|c|c|c|}
\hline & Identidades e Alteridades & Manifestações Religiosas & $\begin{array}{c}\text { Crenças Religiosas e } \\
\text { Filosofias de Vida }\end{array}$ \\
\hline Identificar & 6 & 9 & 10 \\
\hline Reconhecer & 3 & 3 & 10 \\
\hline Respeitar & 2 & 2 & 2 \\
\hline Acolher & 1 & 1 & - \\
\hline Valorizar & 1 & - & - \\
\hline Distinguir & 1 & - & - \\
\hline Caracterizar & 1 & 3 & 1 \\
\hline Exemplificar & - & 2 & 5 \\
\hline Discutir & - & 1 & 6 \\
\hline Analisar & - & - & 1 \\
\hline Debater & - & - & 1 \\
\hline Construir & - & - & \\
\hline
\end{tabular}

Fonte: elaborado pela autora com dados extraídos de Brasil (2018)

O vocabulário escolhido para formulação das Habilidades para o Ensino Religioso é coerente com a proposta epistemológica apresentada pela BNCC. Percebe-se que os verbos que mais se repetem são os que relacionados à observação do fenômeno religioso: identificar e reconhecer. Há que se ressaltar a ocorrência de verbos que remetem à reflexão e posicionamento crítico - elemento que sugere que o objetivo do processo educativo seja a adoção de um propósito pessoal pelo educando, e não a imposição de alguma fé religiosa.

De fato, a escolha dos redatores quanto ao estabelecimento de uma trajetória de desenvolvimento que parte do reconhecimento pessoal à análise do fenômeno, bem como a adoção de um vocabulário que denota um posicionamento crítico do educando enfatizam a opção não-confessional dessa proposta pedagógica. Para além disso, acrescente-se que não apenas as crenças religiosas, mas também as filosofias de vida - como, por exemplo, o ateísmo e o agnosticismo - são contempladas pela BNCC. Esta característica supera à antiga crítica feita aos modelos transconfessionais e interconfessionais do Ensino Religioso (DANTAS, 2004), que validavam o pensamento religioso em detrimento das filosofias de vida.

Tal opção, juntamente com a ênfase na alteridade e o respeito às diferenças, ressalta a coerência do Ensino Religioso apresentado na BNCC com a Constituição Federal (BRASIL, 2017a) e com toda a legislação educacional que a sequencia e segue seus princípios, tais como a LDBEN 9394/96 (BRASIL, 1996) e o Plano Nacional de Educação (BRASIL, 2014a). Seu aspecto de valorização da identidade e da diversidade coaduna com o modelo de nação que se pretende construir a partir do período da redemocratização. Apesar de todas as polêmicas históricas a respeito do Ensino Religioso escolar (CURY, 2004), pode-se afirmar que a proposta para o conteúdo apresentada na BNCC (BRASIL, 2018) serve aos mesmos propósitos apresentados nos documentos que estabelecem os objetivos da educação escolar como um todo, auxiliando na construção da identidade, da cidadania e de uma postura crítica e reflexiva frente a elementos da vida comum.

\section{CONSIDERAÇÕES FINAIS}

É notório que, ao longo de toda a história da educação brasileira, a BNCC tenha sido o primeiro documento curricular cuja escrita considerou uma consulta popular. Para o conteúdo Ensino Religioso, é ainda mais importante, com relação a esse processo, sua manutenção no currículo. Tal permanência pode ser considerada um primeiro passo para sanar dúvidas surgidas em decorrência da trajetória controversa do conteúdo. Após tantas consultas públicas e a especialistas, tem-se o aval do próprio Ministério da Educação de que o Ensino Religioso, sob um determinado modelo, pode contribuir à formação para o exercício da cidadania. 
Pode-se considerar que a trajetória de construção do texto sobre o Ensino Religioso na BNCC teve mais idas e vindas que os documentos de outras áreas do conhecimento e conteúdos. Considere-se que nenhum outro destes chegou a ter sua permanência questionada, nem omitida em alguma das versões preliminares (FONAPER, 2020). Isso não é de se espantar, dada a pluralidade de propostas experimentada até então. A unificação promovida através da BNCC é muito importante, posto que conduz o desenvolvimento epistemológico da área, bem como as possibilidades de formação docente e as propostas metodológicas.

É notório que os conteúdos elencados para o Ensino Religioso na BNCC valorizam o multiculturalismo e a diversidade religiosa. Destaque-se, nesse ínterim, a inserção das filosofias de vida no debate acerca das diferentes religiosidades. Percebe-se ainda que os objetivos de aprendizagem traçados priorizam o reconhecimento e a valorização da identidade do estudante, bem como sua reflexão crítica e posicionamento quanto à própria narrativa de sentido.

É necessário reconhecer que o processo de construção da BNCC teve limitações. Da mesma forma, historicamente, o Ensino Religioso escolar também teve complexidades e incoerências. Ainda assim, a permanência do conteúdo na BNCC, principalmente se considerado que consultas populares foram realizadas durante sua redação, lhe concede novas perspectivas. A maior legitimidade do conteúdo, seu crescimento epistemológico e sua utilidade no processo de construção da cidadania e do reconhecimento das diversidades fazem parte dessas expectativas.

Atualmente, a sociedade se encontra repleta de exemplos de como utilizar o discurso religioso de forma agressiva, preconceituosa e excludente. Espera-se que a presença nas escolas públicas de um Ensino Religioso que valorize a diversidade em todos seus aspectos fomente uma construção social em que essas intolerâncias não mais encontrem espaço. Espera-se que o Ensino Religioso permita aos educandos se reconhecer e construir sua própria identidade, mas também lhes apresente outras identidades e possibilidades, conscientizando sobre o valor da diversidade e o respeito às diferenças.

A presença do Ensino Religioso na BNCC e na educação pública tem por principais pontos positivos a discussão sobre a busca de sentido (religioso ou não) para construção da identidade e projeto de vida dos educandos, a contemplação da diversidade de possibilidades, e seu reconhecimento como igualmente válidas. Nesses aspectos, e não no confessionalismo, deve se embasar a oferta de Ensino Religioso na escolarização pública.

\section{REFERÊNCIAS}

AGUIAR, Márcia Ângela da S. Política educacional e a Base Nacional Comum Curricular: o processo de formulação em questão. Currículo sem Fronteiras, v. 18, n. 13, p. 722-738, set./dez. 2018. Disponível em: < https://www.curriculosemfronteiras.org/vol18iss3articles/aguiar.pdf> . Acesso em: 01 jul. 2020.

BRASIL. Base Nacional Comum Curricular. $1^{a}$ versão. Brasília: Ministério da Educação e Cultura, 2015a. Disponível em: <http://historiadabncc.mec.gov.br/\#/site/inicio>. Acesso em: 23 set. 2018.

BRASIL. Base Nacional Comum Curricular. $2^{\mathrm{a}}$ versão revista. Brasilia: Ministério da Educação e Cultura, 2016a. Disponível em: <http://historiadabncc.mec.gov.br/\#/site/inicio>. Acesso em: 23 set. 2018

BRASIL. Base Nacional Comum Curricular. $3^{a}$ versão. Brasília: Ministério da Educação e Cultura, 2018. Disponível em: <http://basenacionalcomum.mec.gov.br/abase>. Acesso em: 30 mar. 2018.

BRASIL. Constituição (1988). Constituição da República Federativa do Brasil. Brasília: Supremo Tribunal Federal, Secretaria de Documentação, 2017a. Disponível em:

$<$ http://www.stf.jus.br/arquivo/cms/legislacaoConstituicao/anexo/CF.pdf>. Acesso em: 30 mar. 2018

BRASIL. Lei no 13.005 de 25 de Junho de 2014. Diário Oficial da União, Brasília, 26 jun. 2014a. Disponível em: < http://www.planalto.gov.br/ccivil_03/_ato2011-2014/2014/lei/113005.htm>. Acesso em: 17 set. 2018. 
BRASIL. Lei no 9.394 de 20 de Dezembro de 1996. Lei de Diretrizes e Bases da Educação Nacional. Diário Oficial da União, Brasília, 23 dez. 1996. Disponível em: <http://www.planalto.gov.br/Ccivil_03/leis/L9394.htm>. Acesso em: 30 mar. 2018.

BRASIL. Ministério da Educação. Conselho Nacional de Educação. Súmula de pareceres. Diário Oficial da União, Brasília, 20 dez. 2019a, p. 142. Disponível em: < https://www.in.gov.br/web/dou/-/sumula-de-pareceres-234647974>. Acesso em: 19 ago. 2020.

BRASIL. Ministério da Educação. Gabinete do Ministro. Portaria no 592, de 17 de Junho de 2015. Institui Comissão de Especialistas para a Elaboração de Proposta da Base Nacional Comum Curricular. Diário Oficial da União, ed. 114, Brasília-DF, 18 jun. 2015b, p. 16. Disponível em: $<$ http:/ / portal.mec.gov.br/index.php?option $=$ com_docman\&view $=$ download\&alias $=21361$-port-592bnc-21-set-2015-pdf\&category_slug=setembro-2015-pdf\&Itemid=30192>. Acesso em: 19 set. 2018.

BRASIL. Ministério da Educação. Gabinete do Ministro. Portaria n ${ }^{\circ}$ 790, de 27 de Julho de 2016. Institui o Comitê Gestor da Base Nacional Comum Curricular e reforma do Ensino Médio. Diário Oficial da União, ed. 144, Brasília-DF, 28 jul. 2016c, p. 16. Disponível em:

$<$ http://imprensanacional.gov.br/materia/-

/asset_publisher/Kujrw0TZC2Mb/content/id/21776972/do1-2016-07-28-portaria-n-790-de-27-dejulho-de-2016-21776889>. Acesso em: 19 set. 2018.

BRASIL. Ministério da Educação. Parecer do Conselho Nacional de Educação n ${ }^{\circ}$ CP 8. Relator: Ivan Cláudio Pereira Siqueira. Brasília, 08 de outubro de 2019b. Disponível em: <

http://portal.mec.gov.br/index.php?option $=$ com docman\&view $=$ download\&alias $=138411$-pceb00819\&category slug=janeiro-2020\&Itemid=30192> . Acesso em: 19 ago. 2020.

BRASIL. Ministério da Educação. Planejando a próxima década: conhecendo as 20 metas do Plano Nacional de Educação. Brasília: Ministério da Educação / Secretaria de Articulação com os Sistemas de Ensino, 2014b. Disponível em:

<http://pne.mec.gov.br/images/pdf/pne_conhecendo_20_metas.pdf>. Acesso em: 17 set. 2018.

BRASIL. Ministério da Educação. Secretaria de Educação Fundamental. Parâmetros curriculares nacionais: introdução aos parâmetros curriculares nacionais. Brasília: Ministério da Educação e Cultura / Secretaria de Educação Fundamental, 1997. Disponível em: < http://portal.mec.gov.br/>. Acesso em: 01 jan. 2018.

BRASIL. Parecer do Conselho Nacional de Educação n ${ }^{\circ}$ CP 2. Relator: Eduardo Deschamps. Diário Oficial da União, Brasília, 22 dez. 2017b, p. 41-44. Disponível em:

$<$ http://portal.mec.gov.br/index.php?option=com_docman\&view =download\&alias=79631-rcp00217-pdf\&category_slug=dezembro-2017-pdf\&Itemid=30192>. Acesso em: 19 set. 2018.

CÂNDIDO, Rita de Kássia; GENTILINI, João Augusto. Base Curricular Nacional: reflexões sobre autonomia escolar e o Projeto Político-Pedagógico. Revista Brasileira de Política e Administração da Educação, Goiânia, v. 33, n. 2, p. 323-336, maio/ago. 2017. Disponível em: <http://seer.ufrgs.br/index.php/rbpae/article/view/70269>. Acesso em: 18 set. 2018.

CUNHA, Luiz Antônio. A entronização do ensino religioso na Base Nacional Comum Curricular. Educação e Sociedade, Campinas, v. 37, n. 134, p. 266-284, jan./mar. 2016. Disponível em: $<$ http://www.cedes.unicamp.br>. Acesso em: 19 ago. 2020.

CUNHA, Luiz Antônio. Educação e religiões: a descolonização religiosa da Escola Pública. Belo Horizonte: Mazza, 2013.

CURY, Carlos Roberto Jamil. Ensino Religioso na escola pública: o retorno de uma polêmica recorrente. Revista Brasileira de Educação, Rio de Janeiro, n. 27, p. 183-191, set./dez. 2004. Disponível em: <http://www.scielo.br/scielo.php?script=sci_arttext\&pid=S1413-

$24782004000300013>$. Acesso em: 20 set. 2017. 
CURY, Carlos Roberto Jamil. Ensino Religioso: retrato histórico de uma polêmica. In: CARVALHO, Carlos Henrique de; GONÇALVES NETO, Wenceslau (Orgs.). Estado, Igreja e Educação: o mundo ibero-americano nos séculos XIX e XX. Campinas: Alínea, 2010. p. 11-50.

CURY, Carlos Roberto Jamil; REIS, Magali; ZANARDI, Teodoro Adriano Costa. Base Nacional Comum Curricular: dilemas e perspectivas. São Paulo: Cortez, 2018.

DANTAS, Douglas Cabral. O Ensino Religioso escolar: modelos teóricos e sua contribuição à formação ética e cidadã. Horizonte, Belo Horizonte, v. 2, n. 4, p. 112-124, $1^{\circ}$ sem. 2004. Disponível em: < http://periodicos.pucminas.br/index.php/horizonte/article/view/583>. Acesso em: 21 jan. 2018.

FONAPER. Carta de Princípios. Florianópolis, 1995. Disponível em:

<http://www.fonaper.com.br/carta-principios.php >. Acesso em: 17 set. 2017.

FONAPER. Ciclo de Debates 25 anos FONAPER: o Ensino Religioso na Base Nacional Comum Curricular. YouTube, 23 de julho de 2020. Disponível em:

$<$ https://www.youtube.com/watch?v=7VM Wptpl1U\&t=8s $>$. Acesso em: 23 jul. 2020.

FONAPER. Parâmetros Curriculares Nacionais: Ensino Religioso. 9. ed. São Paulo: Mundo Mirim, 2009.

JUNQUEIRA, Sérgio Rogério Azevedo. Ciência da religião aplicada ao Ensino Religioso. In: PASSOS, João Décio; USARSKI, Frank (Orgs.). Compêndio de Ciência da Religião. São Paulo: Paulinas, Paulus, 2013. p. 603-614.

JUNQUEIRA, Sérgio Rogério Azevedo. O processo de escolarização do Ensino Religioso no Brasil. Petrópolis: Vozes, 2002.

JUNQUEIRA, Sérgio Rogério Azevedo; NASCIMENTO, Sérgio Luís do. Concepções do Ensino Religioso. Numen: revista de estudos e pesquisa da religião, Juiz de Fora/MG, v. 16, n. 1, p. $783-$ 810, jan./jun. 2013. Disponível em:

<https://numen.ufff.emnuvens.com.br/numen/article/view/2141>. Acesso em: 19 ago. 2020.

MACEDO, Elizabeth. Base Nacional Curricular Comum: novas formas de sociabilidade produzindo sentidos para educação. Revista e-Curriculum, São Paulo, v. 12, n. 03, p. 1530-1555, out./dez. 2014. Disponível em: <http://revistas,pucsp.br/index.php/curriculum>. Acesso em: 18 set. 2018.

MINISTÉRIO DA EDUCAÇÃO. Base Nacional Comum Curricular (BNCC). [S.1.]: Perguntas frequentes, 2018a. Disponível em: <http://historiadabncc.mec.gov.br/\#/site/faq >. Acesso em: 19 set. 2018.

MINISTÉRIO DA EDUCAÇÃO. Biblioteca. [S.1.]: Preparação, 2018b. Disponível em: <http://historiadabncc.mec.gov.br/\#/site/biblioteca>. Acesso em: 19 set. 2018.

MINISTÉRIO DA EDUCAÇÃO. Coordenação de Aperfeiçoamento de Pessoal de Nível Superior. Sobre as áreas de avaliação. Brasília: Avaliação, 2018c. Disponível em:

<http://capes.gov.br/avaliacao/sobre-as-areas-de-avaliacao>. Acesso em: 26 ago. 2018.

MINISTÉRIO DA EDUCAÇÃO. Princípios que nortearam a Base Curricular estão na

Constituição. [S.1.]: Educação Básica, 2016b. Disponível em: <http://portal.mec.gov.br/ultimasnoticias/211-218175739/34281-principios-que-nortearam-a-base-curricular-estao-na-constituicao $>$. Acesso em: 19 set. 2018.

MINISTÉRIO DA EDUCAÇÃO. Propostas curriculares pelo Brasil. [S.1.]: Preparação, 2018d. Disponível em: <http://historiadabncc.mec.gov.br/\#/site/propostas>. Acesso em: 19 set. 2018.

MOVIMENTO PELA BASE NACIONAL COMUM. Base é entregue ao Conselho Nacional de Educação - Confira tudo! [S.1.]: Novidades sobre a Base, 2017a. Disponível em:

<http://movimentopelabase.org.br/acontece/base-entregue-cne/>. Acesso em: 19 set. 2018. 
MOVIMENTO PELA BASE NACIONAL COMUM. Linha do tempo. [S.1.]: Movimento pela Base Nacional Comum, 2017b. Disponível em: <http://movimentopelabase.org.br/linha-do-tempo/>. Acesso em: 19 set. 2018.

MOVIMENTO PELA BASE NACIONAL COMUM. Quem somos. [S.1.]: Movimento pela Base Nacional Comum, 2017c. Disponível em: < http://movimentopelabase.org.br/quem-somos/>. Acesso em: 19 set. 2018.

MOVIMENTO PELA BASE NACIONAL COMUM. Seminários Estaduais da BNCC: posicionamento conjunto de Consed e Undime sobre a segunda versão da Base Nacional Comum Curricular. [S.1.]: Análises da $2^{\mathrm{a}}$ versão, 2017d. Disponível em: <http://movimentopelabase.org.br/wpcontent/uploads/2016/09/2016_09_14-Relato\%CC\%81rio-Semina\%CC\%81 rios-Consed-eUndime.pdf>. Acesso em: 19 set. 2018.

NEIRA, Marcos Garcia; ALVIANO JÚNIOR, Wilson; ALMEIDA, Déberson Ferreira de. A primeira e segunda versões da BNCC: construção, intenções e condicionantes. EccoS Revista Científica, São Paulo, n. 41, set./dez. 2016, p. 31-44. Disponível em:

<http:/ /www.redalyc.org/articulo.oa?id=71550055003>. Acesso em: 18 set. 2018.

OLIVEIRA, Ricardo de. Ensino Religioso: cultura e inclusão. [S.l.]: Espaço Pedagógico, 2020.

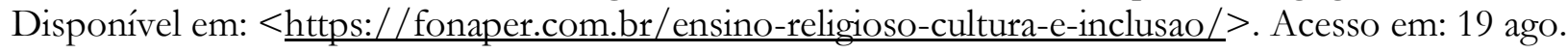
2020

PACHECO, José. Reconfigurar a escola: transformar a educação. São Paulo: Cortez, 2018.

PEREIRA, Deborah Macedo Duprat de Britto. Ação Direta de Inconstitucionalidade no 4439, de 2010. Disponível em:

$<$ http://www.stf.jus.br/portal/geral/verPdfPaginado.asp?id=635016\&tipo=TP\&descricao=ADI\%2F4 439>. Acesso em: 19 ago. 2020.

SAVIANI, Dermeval. História das ideias pedagógicas no Brasil. Campinas: Autores Associados, 2010

SCHOCK, Marlon Leandro. Aportes epistemológicos para o Ensino Religioso na escola: um estudo analítico-propositivo. 2012. 317 f. Tese (Doutorado) - Programa de Pós-Graduação em Teologia, Escola Superior de Teologia, São Leopoldo, 2012. Disponível em:

<http://tede.est.edu.br/tede/tde_busca/arquivo.php?codArquivo=372>. Acesso em: 01 set. 2017.

SIQUEIRA, Giseli do Prado. O Ensino Religioso nas escolas públicas do Brasil: implicações epistemológicas em um discurso conflitivo, entre a laicidade e a confessionalidade num estado republicano. 343 f. Tese (Doutorado) - Universidade Federal de Juiz de Fora, Juiz de Fora, 2012. Disponível em: <https://repositorio.ufjf.br/jspui/handle/ufjf/1967>. Acesso em: 19 ago. 2020.

STF conclui julgamento sobre ensino religioso nas escolas públicas. Brasília: Notícias STF, 2017. Disponível em: < http://www.stf.jus.br/portal/cms/verNoticiaDetalhe.asp?idConteudo=357099>. Acesso em: 31 mar. 2018.

VEIGA, Ilma Passos Alencastro; SILVA, Edileuza Fernandes da. Ensino Fundamental: gestão democrática, projeto político-pedagógico e currículo em busca da qualidade. In: VEIGA, Ilma Passos Alencastro; SILVA, Edileuza Fernandes da (Orgs.). Ensino Fundamental: da LDB á BNCC. Campinas: Papirus, 2018. p. 43-68. 